\title{
ACHADOS PATOLÓGICOS E BACTERIOLÓGICOS EM LESÕES PULMONARES RESPONSÁVEIS POR CONDENAÇÕES DE CARCAÇAS DE SUÍNOS
}

\author{
(Pathological and bacteriological findings in lung lesions responsible for swine \\ carcass condemnations)
}

Marcos Antônio Zanella Morés ${ }^{1}$, Daiane Güllich Donin, Filipe Krasinski Cestari, Geraldo

Camilo Alberton

\section{${ }^{1}$ Correspondência: marcos.mores@embrapa.br}

RESUMO: Um dos principais problemas sanitários da suinocultura é a alta prevalência de doenças respiratórias, que podem ser causadas por uma série de agentes bacterianos e virais. Visando identificar os agentes bacterianos causadores das lesões pulmonares que geram condenação de carcaça de suínos, os pulmões de 150 animais em idade de abate foram submetidos a exames anatomopatológicos e bacteriológicos. Foram escolhidas as lesões pulmonares que causaram o desvio das carcaças na linha do abate para o Departamento de Inspeção Final do Serviço de Inspeção Federal. Pelo exame macroscópico as lesões foram classificadas em broncopneumonia supurativa, broncopneumonia fibrinosa, pleurite ou pneumonia embólica. Na pesquisa bacteriológica isolou-se Pasteurella multocida Tipo D (27,3\%), Pasteurella multocida Tipo A (24\%), Actinobacillus pleuropneumoniae $(13,3 \%)$, Streptococcus suis $(6,7 \%)$, Arcanobaterium pyogenes $(5,3 \%)$ e outras bactérias $(10,0 \%)$. Dentre o total de amostras, 16,7\% foram negativas. As lesões de onde se isolou $P$. multocida e $A$. pleuropneumoniae foram classificadas, em sua maioria, como broncopneumonia fibrinosa ou sequelas desta lesão. Streptococcus sp e $A$. pyogenes relacionaram-se com pequenos abscessos, em lesões com características de pneumonia embólica ou broncopneumonia supurativa.

Palavras-chave: Actinobacillus pleuropneumoniae; Pasteurella multocida; pneumonia; prejuízos ao abate

ABSTRACT: Porcine respiratory disease is one of the most important health problem and can involve multiple viral and bacterial pathogens. Aiming to identify the bacterial agents host in swine, lung from 150 animals in finishing age were submitted to anatomopathologic and bacteriologic tests. Lung lesions that caused carcass rejection to Final Inspection Department from Federal Inspection Service in slaughter line were selected. The macroscopic test classified the lesions in suppurative bronchopneumonia, fibrinous bronchopneumonia, pleuritis and embolic pneumonia. On bacteriologic evaluation Pasteurella multocida Type D (27.3\%), Pasteurella multocida Type A (24\%), Actinobacillus pleuropneumoniae (13.3\%), Streptococcus suis (6.7\%), Arcanobaterium pyogenes (5.3\%) and other bacteria $(10.0 \%)$ were isolated. From the total samples, $16.7 \%$ were negative. The lesions from where $P$. multocida and $A$. pleuropneumoniae were isolated, were classified, in majority, like fibrinous bronchopneumonia or consequences from this lesion. Streptococcus sp. and $A$. pyogenes were related to small abscesses, in lesions with characteristic embolic pneumonia or suppurative bronchopneumonia.

Key Words: Actinobacillus pleuropneumoniae; Pasteurella multocida; pneumonia; losses at slaugther 


\section{INTRODUÇÃO}

As doenças respiratórias, principalmente as pneumonias, estão entre os principais problemas sanitários da suinocultura moderna. Causam perdas por gastos com medicamentos, pioras nos índices zootécnicos e condenações de carcaças. As lesões pulmonares são as principais causas de condenações de carcaças de suínos nos matadouros e podem representar até $50 \%$ do total das condenações (Alberton e Mores, 2008).

A interação entre fatores ambientais e de manejo com os agentes infecciosos presentes nas criações favorece 0 desencadeamento das pneumonias (Opriessnig et al., 2011; Fablet et al., 2012). Os principais agentes infecciosos bacterianos envolvidos são 0 Mycoplasma hyopneumoniae, a Pasteurella multocida e o Actinobacillus pleuropneumoniae (Morrison et al., 1985; Mores et al., 2011). Agentes virais como Influenza A, o Circovírus suíno tipo 2 e o vírus da Síndrome Reprodutiva e Respiratória dos Suínos também são patógenos importantes no complexo respiratório suíno, assim como outros agentes bacterianos (Hansen et al., 2010; Mores et al., 2011).

As pneumonias em suínos são causadas predominantemente por infecções via aerógena, porém infecções por via hematógena também são comuns em suínos de abate. Ao realizar a inspeção sanitária é importante diferenciar as lesões causadas por estas duas vias de infecção, pois de acordo com as regulamentações de inspeção sanitária, carcaças de animais com lesões de broncopneumonia aguda e originadas por processos supurativos devem ser rejeitadas para o consumo (Brasil, 1963; Liljegren et al., 2003).

As informações a respeito de pneumonias em suínos são amplas, consistindo de vários trabalhos relacionados a obtenção de dados epidemiológicos (Opriessnig et al., 2011; Fablet et al., 2012) e com a identificação dos diferentes agentes infecciosos envolvidos nas lesões (Morrison et al., 1985; Hoie et al., 1991; Hansen et al., 2010; Mores et al., 2011), porém são escassos os estudos relacionados especificamente às lesões associadas com condenações de carcaças pelo sistema de inspeção sanitária.

O objetivo deste trabalho foi identificar os agentes bacterianos presentes nas lesões pulmonares responsáveis por desvios de carcaças da linha de abate, condenações e aproveitamento condicional no matadouro, bem como avaliar as características anatomopatológicas das lesões provocadas por estes agentes.

\section{MATERIAL E MÉTODOS}

As amostras foram colhidas no Serviço de Inspeção Federal de um Matadouro - Frigorífico localizado no Estado de Santa Catarina, Brasil. As análises laboratoriais foram realizadas em laboratório de diagnóstico especializado em patologia de suínos localizado no mesmo Estado.

Foram avaliados os pulmões e as carcaças de 150 suínos de um sistema de integração, escolhidos aleatoriamente, dentre aqueles desviados da linha de abate por apresentarem lesões pulmonares. Este número representou $10 \%$ do total de carcaças desviadas por pneumonia no período de estudo. Após a inspeção do veterinário do Serviço de Inspeção Federal, os pulmões foram armazenados individualmente em sacos plásticos novos e imediatamente encaminhados ao laboratório.

As lesões foram descritas quanto a localização e o aspecto macroscópico e, em seguida, separadas em duas 
partes, sendo uma encaminhada para pesquisa bacteriológica e outra para processamento histopatológico. As amostras para histopatologia foram mantidas em formol $10 \%$ tamponado, em temperatura ambiente, durante pelo menos 48 horas. Posteriormente, foram processadas de acordo com as técnicas de rotina padronizadas (Banks, 1993) e as lâminas coradas por hematoxilina e eosina.

As lesões macroscópicas foram classificadas de acordo com López (2007) em: broncopneumonia supurativa, broncopneumonia fibrinosa ou pneumonia embólica.

Amostras em que as lesões envolveram somente a pleura, sem afetar o parênquima pulmonar, foram classificadas como pleurite.

As lesões pulmonares também foram avaliadas quanto ao modelo de distribuição no parênquima pulmonar, sendo classificadas em: crânio ventral (localizadas nos lobos apicais, cardíacos, intermédio e porção anterior dos diafragmáticos); dorso caudal (localizadas nas regiões dorso caudais dos lobos diafragmáticos); e disseminada (distribuídas por todos os lobos pulmonares). Os pulmões amostrados foram classificados também quanto à presença ou ausência de lesões de consolidação pulmonar (preenchimento dos alvéolos por exsudato inflamatório), características de pneumonia enzoótica.

As carcaças dos animais cujos pulmões foram colhidos para o estudo também foram observadas, sendo descritas todas as alterações macroscopicamente visíveis.

Para pesquisa bacteriológica os procedimentos para inoculação das amostras seguiram as descrições de Liljegren et al. (2003). As lesões foram embebidas rapidamente em álcool $70^{\circ} \mathrm{GL}$ e passadas sobre o bico de
Bunsen para eliminação de possíveis contaminações da superfície externa; posteriormente foram cortadas e fez-se a impressão da superfície de corte em duas placas de Ágar Sangue ovino (AS) e uma placa de Ágar Mac Conkey. Uma das placas de AS foi inoculada com uma estria de Staphylococcus aureus nutriz de NAD e incubada em atmosfera de microaerofilia ( $10 \%$ de $\mathrm{CO}_{2}$ ) em jarra de Gaspac com vela. A outra placa de AS foi incubada em atmosfera de anaerobiose. A placa de Ágar Mac Conkey foi incubada em aerobiose. Todas as amostras foram processadas em até 24 horas após a colheita.

A identificação das espécies bacterianas foi realizada de acordo com Quinn et al. (2011). Os tipos capsulares A e D de Pasteurella multocida foram identificados pelos testes de hialuronidase e acriflavina (Carter, 1984).

Devido a frequente inibição do crescimento do $A$. pleuropneumoniae em ágar quando em infecções mistas com $P$. multocida, 35 amostras com lesões macroscopicamente sugestivas de $A$. pleuropneumoniae (pleuropneumonia necro-hemorrágica) foram submetidas ao teste de reação em cadeia da polimerase (nested PCR) para $A$. pleuropneumoniae, utilizando-se como alvo o gene omlA (outer membrane lipoprotein), os primers externos ACP-1F e ACP-2R (458 bp) e primers internos ACP-3F e ACP-4R (444 bp) (Gram e Ahrens, 1998).

\section{RESULTADOS E DISCUSSÃO}

$\mathrm{Na}$ Tabela 1 estão apresentados os tipos de lesões encontrados e sua relação com o resultado da tentativa de isolamento bacteriano. 


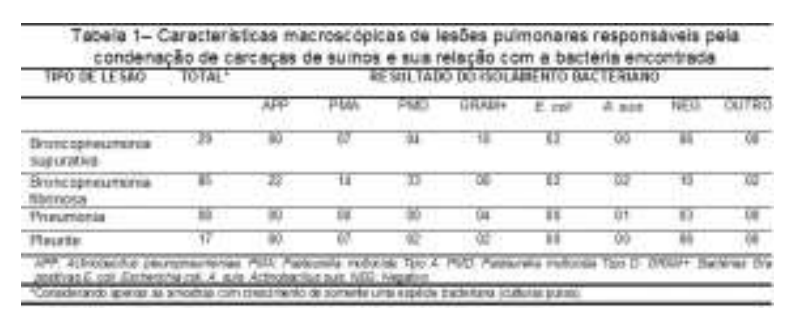

Na Tabela 2 estão os resultados da pesquisa bacteriológica dos pulmões. Em 100 (67\%) amostras, observaramse, além das lesões que causaram o desvio das carcaças, áreas de consolidação do tecido pulmonar, com localização cranioventral, sugestivas de pneumonia enzoótica. $\mathrm{O}$ isolamento bacteriano foi positivo em 125 amostras (83\%). Quanto a localização da lesão no pulmão, em 72 amostras (48\%) as lesões estavam na região dorsocaudal, em $45(30 \%)$ cranioventral e em 33 amostras (22\%), disseminadas no parênquima. A ocorrência de outras lesões nas carcaças foi observada em $47,3 \%$ das amostras, sendo que pleurite (50 amostras), hemorragias na pleura parietal (15 amostras) e caudofagia (06 amostras) foram as mais frequentes.

\begin{tabular}{|c|c|c|}
\hline \multirow[t]{2}{*}{ Bactona } & \multicolumn{2}{|c|}{ KN do amostras (W) } \\
\hline & Totsi & Cuhure Plats \\
\hline P. mulocido Tipo D & $41(27.3)$ & 39 \\
\hline P. melocids Tipa A & $35(240)$ & 23 \\
\hline A pleurepreumoniue & $22(13.3\}$ & 20 \\
\hline Streptococeus \& & $10(8.7)$ & 05 \\
\hline A pyogones: & $08(5,3)$ & $\infty 6$ \\
\hline Corinatonmes & $05\{3,3\}$ & 04 \\
\hline$E$ coll & $05(3.3)$ & at \\
\hline Actinobocilus suls & $03(2,0)$ & 00 \\
\hline Staphylococesus sp & $02(1,3)$ & 01 \\
\hline Pascudamontas ap & $02(1,3)$ & $\omega$ \\
\hline Pastouracla up & $03(2,0)$ & $\infty$ \\
\hline Negrovo & $28(16,7)$ & \\
\hline TOTAL & 100 & 114 \\
\hline
\end{tabular}

A maioria das lesões nas quais apenas a $P$. multocida Tipo $D$ foi isolada caracterizou-se por grandes nódulos de tecido necrótico de coloração amarelada (Figura 1: E-F), envoltos por uma cápsula fibrosa espessa, normalmente com envolvimento de pleura, localizadas principalmente na região dorso caudal do pulmão. Estas lesões, segundo López (2007), são sequelas de broncopneumonias fibrinosas graves. $\mathrm{Na}$ microscopia estas lesões caracterizaram-se por broncopneumonia fibrinosupurativa crônica, com áreas de necrose de coagulação, normalmente envoltas por cápsula de tecido conjuntivo. Espessamento da pleura por hiperplasia do tecido conjuntivo fibroso denso (fibrose) também foi observado nestas lesões.

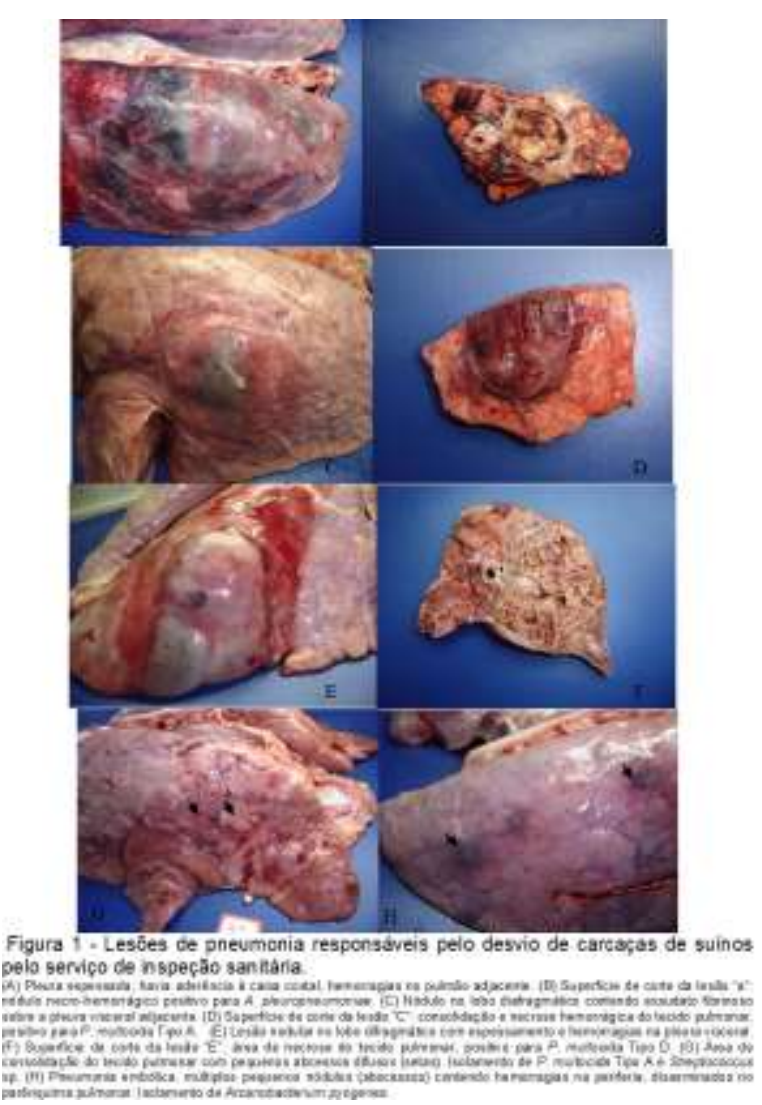

A Pasteurella multocida Tipo A foi isolada principalmente de lesões caracterizadas por áreas de consolidação do parênquima pulmonar, algumas vezes na forma de nódulos com ou sem necrose de coagulação, com exsudação mucopurulenta ou fibrinopurulenta nos brônquios e bronquíolos e deposição de fibrina sobre a pleura visceral (Figura 1: C-D). Estas áreas estavam localizadas principalmente nos lobos cardíacos e diafragmáticos. $\mathrm{Na}$ microscopia, as lesões predominantes foram broncopneumonias ou pleuropneumonias fibrinosupurativas, em alguns casos contendo áreas de 
necrose de coagulação no parênquima pulmonar.

Além das 20 amostras positivas no isolamento bacteriano e PCR, o $A$. pleuropneumoniae foi encontrado em mais duas amostras, somente pelo teste de PCR. As lesões em que este agente foi encontrado consistiram, em sua maioria, por nódulos necrohemorrágicos, únicos ou múltiplos, localizados principalmente nos lobos diafragmáticos, muitas vezes circundados por cápsula fibrosa (sequestro). $\mathrm{O}$ tecido necrótico apresentou coloração amarelo dourado (Figura 1: A-B).

A maioria das amostras onde se identificou $0 A$. pleuropneumoniae foi observado comprometimento da pleura, a qual se apresentava espessada por fibrose e, muitas vezes, com aderências à parede costal, caracterizando a pleuropneumonia crônica. Microscopicamente as lesões de $A$. pleuropneumoniae se caracterizaram por pleuropneumonia necrohemorrágica, com exsudação acentuada de fibrina, principalmente nos espaços interlobulares, os quais se apresentavam com intensa dilatação e trombose nos vasos linfáticos. Abundante quantidade de leucócitos alongados (oat cells) foram observados na periferia das áreas em necrose de coagulação. Foi observado também, em algumas amostras, trombose e vasculite.

As bactérias Gram positivas, Arcanobacterium pyogenes, Streptococcus sp e outras bactérias do grupo corineformes, foram encontradas em lesões semelhantes. Em oito destas amostras as lesões foram classificadas como pneumonia embólica e consistiram de pequenos abscessos (menores que $0,5 \mathrm{~cm}$ de diâmetro) disseminados por todos os lobos do parênquima pulmonar e foram associados a lesões de caudofagia ou artrite na carcaça (Figura 1H). Nas demais amostras apareceram pequenos abscessos, semelhantes aos descritos acima, porém localizados na região cranioventral do pulmão, em meio às lesões de consolidação pulmonar (Figura 1G), sugerindo infecção aerógena. Em menor frequência, lesões somente de consolidação pulmonar ou pleurite crônica também estiveram associadas a estes agentes. $\mathrm{Na}$ histolopatologia estas lesões foram características de abscessos, contendo grumos de bactérias Gram positivas em meio a exsudato purulento. O agente Actinobacillus suis foi isolado em três amostras, sendo que duas apresentaram distribuição compatível com infecção aerógena; a terceira amostra apresentou pequenos nódulos purulentos disseminados pelos lobos diafragmáticos sugerindo infecção hematógena.

Em cinco amostras classificadas como broncopneumonia isolou-se Escherichia coli, sendo que as lesões apresentavam localização cranioventrais e foram caracterizadas por áreas de consolidação de consolidação vermelha. Em quatro destas amostras o exame histopatológico revelou áreas de pneumonia granulomatosa com formação de células gigantes sugerindo pneumonia por corpo estranho, sendo que em duas destas amostras foi possível observar estruturas sugestivas de tecido vegetal na lesão.

A identificação da $P$. multocida e do $A$. pleuropneumoniae como agentes mais frequentes em lesões pulmonares que geram desvio e condenação de carcaças no abatedouro está de acordo com outros trabalhos (Hoie et al., 1991; Hansen et al., 2010; Mores et al., 2011) que demonstram estes agentes entre os mais encontrados em pneumonias em suínos. Conforme López (2007), estes dois agentes são os principais causadores de broncopneumonias fibrinosas em suínos, o que também foi confirmado neste estudo. Segundo o 
mesmo autor, as principais sequelas das broncopneumonias fibrinosas em suínos são pleurites crônicas, nódulos e abscessos pulmonares. Estas lesões foram as mais frequentes causas de desvios e condenações de carcaças no presente estudo. Foi observado que a $P$. multocida Tipo A e $P$. multocida Tipo D e 0 A. pleuropneumoniae causam lesões com características macroscópicas semelhantes, não sendo possível diferenciá-las sem análise microbiológica.

O $M$.

M. hyopneumoniae é considerado um dos principais patógenos respiratórios dos suínos (Hansen et al., 2010), porém as lesões provocadas por este agente, caracterizadas apenas por consolidação pulmonar ou broncopneumonia supurativa não estão associadas com desvios ou condenações de carcaças. Por esta razão e pelo objetivo deste trabalho, este agente não foi pesquisado, contudo seu papel como agente primário, principalmente nas lesões onde a $P$. multocida foi isolada, deve sempre ser considerado. Isto fica evidente quando se observa que em $67 \%$ das amostras encontraram-se, além da lesão causadora do desvio da carcaça, áreas de consolidação pulmonar cranioventrais, compatíveis com infecção pelo M. hyopneumoniae.

$\mathrm{O}$ achado de um maior percentual de amostras de $P$. multocida Tipo $\mathrm{D}$ em relação ao Tipo A difere de outros estudos realizados, nos quais $O$ sorogrupo capsular A foi encontrado sempre em mais de $90 \%$ das amostras de $P$. multocida isoladas de lesões pulmonares em suínos (Morrison et al., 1985; Hoie et al., 1991; Borowski et al., 2002). Porém Jordan et al. (2006), relatam um crescente envolvimento de amostras do grupo $D$ em pneumonias. A maior prevalência de cepas do grupo $D$ encontrada pode estar relacionada a fatores imunossupressores nos animais. Há relatos da associação de micotoxinas predispondo infecção por $P$. multocida em suínos (Halloy et al., 2005). Jordan et al. (2006) também citam a imunossupressão como provável responsável pelo crescente envolvimento da $P$. multocida Tipo $D$ em pneumonias em suínos nos EUA.

$$
\text { O isolamento de } A \text {. }
$$

pleuropneumoniae em $14,7 \%$ das amostras é um achado semelhante ao trabalho de Hoie et al. (1991), que trabalhou com lesões de pneumonia crônica, porém difere de outros trabalhos (Liljegren et al., 2003; Wallwitz de Araújo, 2004), onde este agente não foi encontrado. Esta diferença pode estar relacionada aos tipos de lesões selecionadas para os trabalhos, pois no presente estudo foram amostradas lesões de pneumonia predominantemente crônicas, enquanto que os autores citados trabalharam especificamente com abscessos pulmonares.

Nas duas amostras positivas para A. pleuropneumoniae pelo teste de PCR, e negativas para este agente no isolamento bacteriano, observou-se crescimento de $P$. multocida e Pseudomonas spp. $O A$. pleuropneumoniae é um agente de crescimento mais lento, sendo inibido por outros microrganismos como a $P$. multocida, conforme descrito por Christensen et al. (1999), o que pode explicar o não isolamento desta bactéria nestas amostras.

$\mathrm{O}$ isolamento de bactérias Grampositivas em lesões pulmonares de suínos é relatado por vários autores (Hoie et al., 1991; Wallwitz de Araújo, 2004), sendo principalmente descritos Streptococcus sp, Arcanobacterium pyogenes e as bactérias do grupo denominado corineformes. Estes agentes podem causar broncopneumonia por infecção via aerógena, normalmente secundários a outras infecções, ou pneumonia embólica, por disseminação 
hematógena (López, 2007). Neste estudo ambos os modelos de disseminação foram encontrados.

Dos 150 suínos avaliados, 117 (78\%) apresentaram pneumonia com modelo de distribuição cranioventrais ou dorsocaudais localizadas, característica de infecção via aerógena. Adicionalmente, os achados de fibroses teciduais que caracterizam as lesões como crônicas foram observados em 109 (73\%) amostras. Estas observações são de extrema importância para o Serviço de Inspeção de carnes, pois caracterizam as lesões como de baixo risco para a saúde pública. De acordo com a Legislação Brasileira (Brasil, 1963) e da União Européia (Liljegren et al., 2003) as restrições de consumo devem ser aplicadas às carcaças de suínos com lesões pulmonares de broncopneumonia aguda ou aquelas relacionadas com bacteremia, ou seja, disseminação hematógena do agente causador.

As lesões de pneumonia embólica, disseminadas via hematógena, que representam maior risco de veiculação de contaminações via carcaças, foram observadas em apenas $5,3 \%$ das amostras avaliadas. Estas lesões podem ser identificadas por uma avaliação macroscópica cuidadosa levando-se em consideração o modelo de distribuição da lesão no parênquima pulmonar, as próprias características das lesões e a presença de outras alterações nas carcaças, como caudofagia, lesões de pele ou cascos e artrites, as quais atuam como portas de entrada para as bactérias causadoras da septicemia. Neste estudo lesões de caudofagia foram as mais frequentes.

\section{CONCLUSÃO}

As principais lesões pulmonares responsáveis pelo desvio e condenações de carcaças de suínos pelo Serviço de Inspeção sanitária são nódulos e abscessos pulmonares, lesões estas sequelas das broncopneumonias fibrinosas. Os principais agentes bacterianos encontrados nestas lesões, em ordem decrescente de prevalência foram Pasteurella multocida Tipo D, Pasteurella multocida Tipo A e Actinobacillus pleuropneumoniae. Com frequência bem menor aparecem as pneumonias embólicas, onde os principais agentes encontrados foram Streptococcus sp e Arcanobacterium pyogenes.

\section{REFERÊNCIAS}

ALBERTON, G. C.; MORES, M. A. Z. Interpretação de lesões no abate como ferramenta de diagnóstico das doenças respiratórias dos suínos. Acta Scientiae Veterinariae, Porto Alegre, v. 36, n. 1, p.95-99, jan. 2008.

BANKS, J.W. Applied Veterinary Histology, 3Ed. St. Louis: Mosby-Year Book, 1993, 527p.

BOROWSKI, S.M.; IKUTA, N.; LUNGE, V. et al. Caracterização antigênica e fenotípica de cepas de Pasteurella multocida isoladas de pulmões de suínos com pneumonia e/ou pleurite. Pesquisa Veterinária Brasileira, 27 (3): 97-103, 2002.

BRASIL. Ministério da Agricultura, Pecuária e Abastecimento. Departamento de Inspeção de Produtos de Origem Animal.1963. Decreto no 1255, de 25.06.62 - Diário Oficial da União no de 04.07.63 - Regulamento da inspeção industrial e sanitária de produtos de origem animal. Online. Disponível na internet: $<$ http://www.agricultura.gov.br/animal/m ercado-interno/requisitos-sanitarios $>$. Acesso em: 21 abr. 2016.

CARTER, G.R. Serotyping of Pasteurella multocida. In: Bergan T. Methods in Microbiology, London, 1984. Chap. 16, p. 247-258. 
CHIERS K.; DONNÉ, E.; OVERBEKE, I. $\mathrm{V}$. et al. Evaluation of serology, bacteriological isolation and polymerase chain reaction for the detection of pigs carrying Actinobacillus pleuropneumoniae in the upper respiratory tract after experimental infection.Veterinary Microbiology, v.88 n.4 p.385-392, 2002.

CHRISTENSEN G.; SØRENSEN, V.; MOUSING, J. Diseases of the respiratory system. In: Leman A., Straw B.E., Mengeling W. L., D`Allaire S. \& Taylor. D.J. Diseases of swine. 8th. Ames: lowa State University Press, 1999, p. 913-940.

FABLET, C; MAROIS-CRÉHANB, C.; SIMON, G. et al. Infectious agents associated with respiratory diseases in 125 farrow-to-finish pig herds: A crosssectional study. Veterinary Microbiology, v.157, p.152-163, 2012.

GRAM, T. \& AHRENS, P. Improved diagnostic PCR assay for Actinobacillus pleuropneumoniae based on the nucleotide sequence of an outer membrane lipoprotein. Journal of clinical microbiology, v. 36, n.2, p. 443 - 448, 1998.

HALLOY D. J.; PASCAL, G. G.; SANDRINE, B. et al. Oral exposure to culture material extract containing fumonisins predisposes swine to the development of pneumonitis caused by Pasteurella multocida. Toxicology, v. 213 n.1-2, p. 34-44, 2005.

HANSEN, M.S.; PORS, S. E.; JENSEN, $H$. E. et al. An investigation of the Pathology and Pathogens Associated with Porcine Respiratory Disease Complex in Denmark. Journal of Comparative Pathology, v. 143(2-3), p.120-131, 2010.

HOIE, S.; FALK, K.; LIUM, B. M. An abattoir survey of pneumonia and pleuritis in slaughter weight swine from 9 selected herds. IV. Bacteriological findings in chronic pneumonic lesions.
Acta Veterinaria Scandinavia, v.32, n.3, p. 395-402, 1991.

JORDAN D.; HOFFMAN, L.; THACKER, E. Pasteurella multocida as a component of porcine respiratory disease complex (PRDC), 2006. Proceedings of the American Association of Swine Practitioners, pp. 149-152.

LILJEGREN, C. H.; AALBAEK, B.; NIELSEN, O. L. et al. Some new aspects of the pathology, pathogenesis, and etiology of disseminated lung lesions in slaughter pigs. Acta

Pathologica Microbiologica et Immunologica Scandinavica, v.111, n.5, p.531-538, 2003.

LÓPEZ, A. Respiratory System. In: McGAVIN, M.D.; ZACHARY, J. F. Pathologic Basis of Veterinary Disease. 4. ed. St. Louis: Mosby, 2007. Chap. 9, p. 463-558.

MORES, M. A. Z.; KUCHIISHI, S. S.; ASCOLI, K. R. et al. Etiologia de problemas respiratórios em suínos enviados ao Cedisa para diagnóstico no ano de 2010. In: XV CONGRESSO BRASILEIRO DE VETERINÁRIOS ESPECIALISTAS EM SUÍNOS, 2011. Fortaleza, RS, CD Room.

MORRISON, R. B.; PIJOAN, C.; HILLEY, H. D. et al. Microorganisms associated with pneumonia in slaughter weight swine. Canadian Journal of Comparative Medicine, v. 49, n.2, p. 129-137, 1985.

OPRIESSNIG, T.; GIMÉNEZ-LIROLA, L. G.; HALBUR, P. G. Polymicrobial respiratory disease in pigs. Animal Health Research Reviews v.12, n.2, p. 133-148, 2011.

QUINN, P. J.; MARKEY, B. K.; LEONARD, F. C. et al. Clinical Veterinary Microbiology. Ames: lowa, 2011. 648p. 
WALLWITZ DE ARAÚJO, A. O. W. Abscessos pulmonares em suínos abatidos industrialmente: bacteriologia, anatomopatologia e relação entre portas de entrada e lesões macroscópicas. 2004. 86f. Dissertação (Mestrado em Medicina Veterinária Preventiva), Programa de Pós-graduação em Ciências Veterinárias da Faculdade de Veterinária - UFRGS, Porto Alegre/RS.

VAZ, C.S.L.; SILVA, S.C. Aspectos recentes da patogênese e diagnóstico da pleuropneumonia suína. Ciência Rural, Santa Maria, v. 34, n. 2, p. 635$643,2004$. 